\title{
EVALUATION OF ONLINE PROGRAMMES: CONSTRUCTING THE SEA-EU TOOLKIT
}

\author{
Josef Trapani, Maria Cassar, Ermira Tartari, Faculty of Health Sciences, Veronica
} Montebello, Faculty of Dental Surgery, Adrienne Grech, Faculty of Health Sciences, Stefan Attard, Faculty of Theology, Michelle Camilleri, Faculty of Health Sciences, University of Malta, L-Imsida, Malta

\section{Abstract}

The COVID-19 pandemic brought online learning to the forefront of education across the globe. Educational institutions were forced to develop and deliver online programmes of study at a manner and pace that left many unprepared. A year and a half into the pandemic, the need for review and evaluation of swiftly developed online programmes is clearly indicated. This paper presents the process of developing a toolkit for evaluating online programmes by academics from the six partners of the European University of the Seas (SEA-EU) project. The toolkit provides a user-friendly guide for educators, managers and stakeholders in the education field, seeking to assess the quality of online programmes. The toolkit development process is extensively described in order to highlight its potential and the usefulness of collaborative work amongst international academic partners.

\section{Introduction}

The last two decades have witnessed new approaches to education wherein digitally mediated teaching and learning have slowly increased as a result of higher demand. With the COVID-19 pandemic, the education programmes of more than 1.38 billion learners were abruptly disrupted due to physical campuses being shut down to prevent the spread of infection (McCarthy, 2020). As a result, education providers and students across the globe had to shift to, optimise, or increase online learning endeavours, often without adequate pedagogical and practical preparedness. For educators with digital experience, the new, and now contemporary, reality of online dominance in the field of education triggered by the pandemic, was easily embraced and opportunities for evaluation of online programmes enhanced. Educators with less technological expertise may feel less confident. 
In this context, this paper describes the process of developing a toolkit which guides the design, delivery and evaluation of an online programme. The comprehensive and userfriendly nature of the toolkit should empower educators with variable levels of proficiency and confidence in technology and online education. The toolkit was constructed by a team of academics from the six partners of the European University of the Seas (SEA-EU) project, namely the University of Cádiz (Spain), University of Malta (Malta), University of Gdańsk (Poland), University of Split (Croatia), Université de Bretagne Occidentale in Brest (France) and Kiel University (Germany). A description of the process and its evaluation is presented, in view of highlighting the potential of this resource, the usefulness of collaborative work amongst international academic partners as well as lessons learnt from the process.

This toolkit fits the rollout of the European Commission (EC)'s wider action plan regarding digital education, in that it contributes towards the engagement of educators in assessing and evaluating online programmes, despite disparities in their training and experience in online teaching and learning. Indeed, through its Digital Education Action Plan, the EC is committed to support the equal development of online and digital education across all member states, irrespective of the emergence and intensity of the COVID-19 pandemic (EC, 2018).

\section{Toolkit development process}

\section{Preparation}

The toolkit was developed during an online five-day workshop with representatives from all six SEA-EU members. The process included a variety of strategies and a balance between different guiding principles. In particular, the investigators wanted to achieve a balance between:

- A top-down and a bottom-up approach (Dudinik \& Berge, 2006; Martinich, 2016);

- Adopting an emergent design while retaining a loose underpinning structure;

- Using the existent literature and the participants' experience and perspectives as sources for the toolkit;

- Having a pre-established schedule while being sensitive to the need to adapt it according to the developments of, and work completed along, the workshop, in the spirit of collaborative practice;

- Safeguarding all the participants' right to make their input noted while ensuring that the toolkit was devised within the allocated time of one week.

Prior to the workshop, the organisers identified four key themes that were proposed as the starting blocks of the toolkit. The themes were (a) building a community of learners (Garrison, 2007), (b) teaching presence in online learning (Anderson et al., 2001), (c) 
Trapani, J., Cassar, M., Tartari, E., Montebello, V., Grech, A., Attard, S., \& Camilleri, M.

Evaluation of Online Programmes: Constructing the SEA-EU Toolkit

scaffolded learning and teaching strategies (Jumaat \& Tasir, 2014; Shaw, 2019) and (d) approaches to assessment. These themes were determined on the basis of a literature search and on the organisers' own experience in designing and delivering online programmes. The organisers of the workshop were all experienced academics who had received training in online learning.

The first day of the workshop was dedicated to presentations by the delegation from each of the six partner universities about the strategies to online learning adopted at their institution and a keynote speech about what needs to be evaluated in online learning. The aim of both activities was to trigger the participants' reflection about their own and other participants' achievements and limitations in online learning and to enhance their sensitivity to the necessary considerations in achieving the main intended outcome of the workshop - that of collaboratively creating a comprehensive toolkit to evaluate online programmes.

\section{Work in thematic groups}

On the second day, following a brief presentation about the value of toolkits in education in general and in online learning in particular, the participants were divided into four groups according to the theme they had chosen at registration, on a first-come-first-served basis. Discussion took place in previously created Zoom breakout rooms.

The work within the thematic groups commenced by looking at a working definition of the respective themes. The pedagogical approaches of scaffolding (Jumaat \& Tasir, 2014), building a learning community (Garrison, 2007), teaching presence (Garrison \& Cleveland-Innes, 2005) and assessment strategies are well supported in both face to face and online learning environments (Lave \& Wegner, 1991; Thompson \& Macdonald, 2005; Shea et al., 2006). The thematic groups identified different working approaches, with some opting to carry out a literature search for any relevant theoretical background and others drawing upon their experiences in online education to inform the salient aspects of the toolkit.

\section{Building a community of learners}

The first thematic group acknowledged that building communities online is an increasingly challenging task, when compared to face-to-face education (Slagter van Tryon \& Bishop, 2009). Thus, the group commenced by focusing on barriers that students face when engaging and trying to form part of an online community and shifting the perspective from a course designer to a learner. To minimise these challenges, the concept of universal design and accessible social content were implemented within the framework. The availability of different platforms and methods through which learners can participate in online environments, with a focus on achieving learning outcomes using different active 
learning strategies, was a predominant theme in these discussions. The initial working document of this thematic group consisted of the distribution of concepts within three phases of online programme evolution: introduction, implementation and evaluation. The introductory phase included assessment of learner needs and expectations, netiquette guidelines, programme policies, creation of profile pages, calendars and icebreakers, as well as the creation of fora for communication. The implementation phase focused on strategies that facilitate discourse and engage learners in knowledge and skill competencies. The concluding phase incorporated the evaluation of strategies used in the overall teaching and learning, in relation to timely feedback and self, peer, external and learner evaluation. Initially all strategies were further divided into strategies for learners and educators. However, the group decided to remove this distinction since, in itself, it created an unnecessary divide within the community of learners that was being promoted, with the educator being a learner as well.

\section{Teaching presence in online learning}

This thematic group discussed the need to shift the emphasis from preparing face-to-face sessions to (a) designing course-units which define learning goals; (b) plan effective feedback and assessment; and (c) identify what teaching and learning activities will be used to support students achieve such learning goals. The group proposed an evaluation checklist to guide course development, planning and implementation and to improve course delivery, with the aim of understanding students' expectations and needs. In the second stage, the group discussed instances during the students' learning journey where teaching presence could influence learning and further categorised teaching presence into facilitation of discourse, engaging students, monitoring learning and content delivery. A list of activities and practices which may be used by educators to evaluate the categories of teaching presence was created including: icebreakers, netiquette policies, the importance of encouraging, acknowledging and reinforcing students' contributions, and prompting and guiding discussions to focus on the learning outcomes. Active feedback from students at regular intervals, peer evaluation, self-evaluation and self-reflection with an opportunity for professional growth were identified as effective evaluation methods for teaching presence during course delivery. Participants discussed how teaching presence is also determined through focused direct instruction, which encompasses scholarly leadership and pedagogic competence. Faculty members tasked with online teaching should be provided with online education related to course development and instructions on proper technology use to ensure they are adequately trained to provide high quality online programmes. The working group offered insight into the need to evaluate programme delivery in terms of whether the minimum course expectations were reached by analysing data from results of tests, exams, tasks and using social media and associated diagnostics for evaluation. Evaluating teaching presence after online programme completion was 
Trapani, J., Cassar, M., Tartari, E., Montebello, V., Grech, A., Attard, S., \& Camilleri, M.

Evaluation of Online Programmes: Constructing the SEA-EU Toolkit

deemed vital. Formal, documented self-evaluation, peer evaluation, evaluation by external examiners/experts, evaluation through computer analytics and data metrics and student evaluation are all methods which may be used for this purpose.

\section{Scaffolded teaching and learning}

This thematic group identified the necessary criteria that would assist educators to effectively embed the technique of scaffolding in the very matrix of an online programme. First, the main literature on this technique was consulted, discussed and sifted through, in order to select that which was highly scholarly. Second, a brainstorming session of the most pertinent elements of scaffolding was carried out, making sure to cover as large a span of the online programme as possible, particularly the design and delivery phases. Third, a Scaffolded Technique Checklist was developed. This took practically every facet of the learning process into consideration in order to ascertain that a variety of tools are employed to enhance knowledge in the resulting well-structured, smooth running programme. Hence, for instance, the following topics were analysed and incorporated into the Checklist: the learning outcomes; the use of a roadmap and a clear timeline; tools and activities adopted in order to attain the learning outcomes; awareness of knowledge gaps and diverse learning types of students; the use of rubrics; student interaction through peer feedback; and tutor feedback to students given over a particular period of time.

\section{Approaches to assessment}

The final thematic group discussed and compiled standards for educators in relation to approaches to assessment for online learning. The focus of the discussion revolved around aspects of measuring and gauging the effectiveness of evaluation strategies in online learning environments. Ongoing self-evaluation by educators and learners during all the phases of the course (before, during and upon course completion) is paramount. Through continuous feedback and regular appraisal mechanisms, the students' satisfaction, participation and progress can be observed and assessed. An evaluation of the possibility to learn from errors and a tolerance for discussion must be fostered in order to accommodate the above. The aim of direct and indirect assessments should be in line with course objectives, irrespective of the process itself. The group engaged in brainstorming, which identified the importance of accounting for learners' different needs and allowing for flexibility. Regular revision of facilitation methods, based on virtual learning environment data analytics and students' feedback on the learning experience, lead to constant improvement and enhancement of a programme. Providing students with individual and timely feedback was identified as a crucial element highlighting the importance of taking action on feedback provided by students and ways and means of relaying the feedback back to the learners and educators. Formative assessments consisting of ongoing evaluation of teaching effectiveness and student learning are important and 
should be performed multiple times during an online programme. Summative assessments are recommended to evaluate learning at the end of the programme and to identify if the intended learning outcomes have been achieved. The group also identified all the elements of assessment throughout the stages of online learning. A wide range of assessment tools and methods to evaluate the learning progress, knowledge and skill acquisition by adapting to the educational needs of the students were discussed.

The collective outputs of the thematic groups consisted of:

- A working document identifying the salient elements to be considered in view of adopting a scaffolded approach to learning;

- A question based checklist for evaluating strategies in relation to building a community of learners within each phase of an online programme;

- A diagrammatic representation of the central components which are to be considered when evaluating effective teaching presence.

- An algorithm incorporating key elements of assessment at different stages of the online learning process that need to be taken into account when planning, coordinating and delivering online learning.

\section{Collating and refining the toolkit}

The following questions were shared to help each group refine and report their work to the rest of the participants:

- Which of the points identified by this group are most important/relevant in evaluating the process of online teaching and learning?

- What points identified by this group work are less important/relevant in such evaluation?

- What modifications do we need to make in our group work to fit the overall toolkit?

The subsequent discussion revealed substantial commonalities and overlap across the outputs of the first two (Building a community of learners and Teaching presence) and the last two (Scaffolded learning/teaching strategies and Approaches to assessment) thematic groups. Thus, participants were accordingly regrouped into two larger groups. By the fourth day, the emerging toolkit incorporated two distinct, yet interrelated, elements: textual and diagrammatic. Therefore, participants were reassigned to two groups on the basis of their preference and perceived potential contribution to the artistic or the linguistic element of the emerging toolkit. These realigned groups respectively produced: (a) a set of guiding principles and reflective questions directing the evaluation of online programmes; and (b) a roadmap visually depicting various strategies and methods of evaluation in different phases before, during and after the delivery of an online programme. 
Trapani, J., Cassar, M., Tartari, E., Montebello, V., Grech, A., Attard, S., \& Camilleri, M.

Evaluation of Online Programmes: Constructing the SEA-EU Toolkit

On the final day of the workshop, three teams were formed. The first team formulated a preamble and the general guiding principles and intended outcomes of the toolkit. The second team refined the reflective questions for evaluating each phase of an online programme and their location in the emerging roadmap. The third team built a glossary of key terms used in the toolkit and collated a set of external resources that may be helpful to its users. The last part of the workshop was dedicated to discuss plans for dissemination. Final editorial refinements to the entire toolkit were addressed by the organisers. Since this is intended as a 'live' toolkit, a rotation between partners for its maintenance along the duration of the SEA-EU project was agreed by all universities.

\section{The Outcome}

Several strategies included in the toolkit draw upon concepts of the Community of Inquiry (COI) framework (Garrison, 2016), through supportive discourse and setting the appropriate climate for the facilitation of social connectedness, promoting a culture of collaboration and encouraging self-reflection. Garrison identified three pillars that relate to online educational experiences: teaching, social and cognitive presence. Teaching presence refers to how well the educator communicates goals and learning objectives, motivates and engages participants and provides timely feedback. Social presence occurs when participants identify with the online community and develop relationships with both peers and faculty. Cognitive presence encourages participants to foster critical thinking and integrate learning principles into real life practical situations. The interaction between all three pillars is fundamental to foster positive learning outcomes (Garrison, 2016).

By the end of this project, it was clear that the COI framework not only positively impacted the design and development of the toolkit, but, in a parallel process, we too, as academics, were also using Garrison's three pillars of teaching, social and cognitive presence, particularly as a result of the diversity amongst all involved. The optimal and maximal contribution of several delegates from all participating partners was challenging in many ways, such as having limited shared knowledge of each individual's expertise, diverse knowledge and experience in teaching online, as well as some participants leaving the workshop periodically due to other commitments. The organisers sought to mitigate challenges in various ways, for example, by creating shared documents that can be worked upon simultaneously over a period of five days, even if participants were not in attendance of a group meeting. This allowed for asynchronous participation and provided a space for reflection and opportunities for reviewing individuals' contributions.

In the spirit of a developing community of inquiry, a toolkit was created. This consists of: (a) a preamble delineating its intended aims and process of updating through the duration of the SEU-EU project; (b) an introductory section explaining the underpinning elements 
of online teaching; (c) a roadmap and explanatory notes facilitating its use; (d) definitions, objectives and guiding questions for evaluating the introductory, implementation and concluding phases of an online programme; (e) a glossary and bibliography. A segment of the toolkit under construction is presented in Figure 1. The toolkit shall be presented more extensively in a forthcoming collaborative publication by the SEA-EU project.

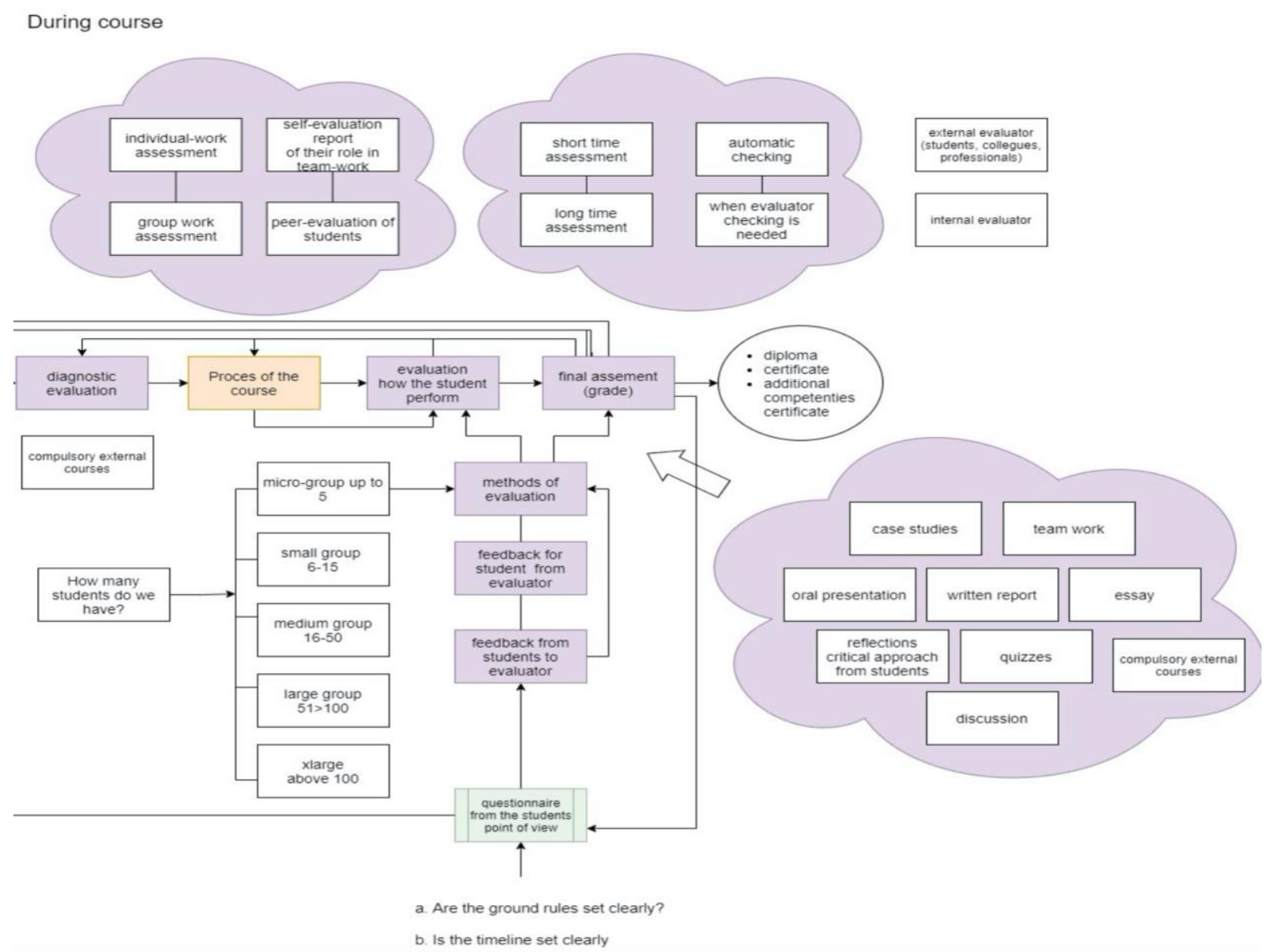

Figure 1. A segment of the SEA-EU toolkit for evaluating online programmes under construction

\section{Process Evaluation}

Feedback from the participants was sought at the end of the workshop. The vast majority of the respondents were very satisfied with the process and outcome of the workshop. Most of the participants felt that their intended outcomes were achieved to a substantial (46.7\%) or to a large (26.7\%) extent, and almost all the participants felt that their perspective about online learning had changed, either slightly (73.3\%) or substantially (13.3\%). The participants praised the collaborative nature of the workshop across different universities, the sharing of good practices and the moderators' balance between leading and incorporating the participants' input. The use of smaller breakout rooms and the moderators' flexibility and openness to the participants' views, not only about the content of the toolkit being developed but also about the process used in the different stages of the workshop, were received favourably. Less positive feedback included the intensive work 
Trapani, J., Cassar, M., Tartari, E., Montebello, V., Grech, A., Attard, S., \& Camilleri, M.

Evaluation of Online Programmes: Constructing the SEA-EU Toolkit

involved, the varying commitment of other participants and an occasionally rushed pace with inadequate time for reflection.

\section{Conclusion}

The SEA-EU toolkit provides a basic framework and set of instruments for assessing the design, delivery and evaluation of an online programme. Against a backdrop of the sudden rise in the demand and use of online programmes, it is believed that this toolkit is relevant and timely. The basic nature of the toolkit and the methodological process used to develop it, involving an eclectic group of educators, should lend themselves well towards its effective use. This, in turn, augurs well towards the accomplishment of the referred EC's (2018) commitment to supporting the equal development of online and digital education across its member states.

The potential of this toolkit stems from the process of its development, which was described in paper, wherein a group of educators from six European tertiary education institutions drew upon the literature, theory, experience and knowledge in a collaborative manner. The adopted methodology is believed to be underpinned by significant robustness and fitness of the toolkit produced as its output, and should be considered of relevance to educators and managers at national and international levels.

\section{References}

Anderson, T., Rourke, L., Garrison, D. R., \& Archer, W. (2001). Assessing teaching presence in a computer conferencing context. Journal of Asynchronous Learning Networks, 5(2), 1-17. Retrieved from https://olj.onlinelearningconsortium.org/index.php/olj/article/view/1875/706

Dudinik, G., \& Berge, Z. L. (2006). Balancing Top-Down, Bottom-Up, and Peer-to-Peer Approaches to Sustaining Distance Training. Turkish Online Journal of Distance Education, 7(3), 144-153. Retrieved from https://dergipark.org.tr/en/download/article-file/156430

European Commission (2018). European Commission Digital Education Action Plan.

Retrieved from https://eur-lex.europa.eu/legalcontent/EN/TXT/?uri=COM:2018:22:FIN

Garrison, D. (2007). Online Community of Inquiry Review: Social, Cognitive, and Teaching Presence Issues. Journal of Asynchronous Learning Networks, 11(1), 61-72. Retrieved from http://eric.ed.gov/?id=EJ842688

Garrison, D. (2016). E-Learning in the $21^{\text {st }}$ Century: A Community of Inquiry Framework for Research and Practice ( $3^{\text {rd }}$ ed.). London, UK: Routledge. 
Trapani, J., Cassar, M., Tartari, E., Montebello, V., Grech, A., Attard, S., \& Camilleri, M.

Evaluation of Online Programmes: Constructing the SEA-EU Toolkit

Garrison, D., \& Cleveland-Innes, M. (2005). Facilitating cognitive presence in online learning: Interaction is not enough. The American Journal of Distance Education, 19, 133-148. doi:10.1207/s15389286ajde1903_2

Jumaat, N. F., \& Tasir, Z. (2014). Instructional scaffolding in an online learning environment: A meta-analysis. Proceedings of the IEEE, 74-77. doi:10.1109/LaTiCE.2014.22

Lave, J., \& Wenger, E. (1991). Situated learning: Legitimate peripheral participation. Cambridge, UK: Cambridge University Press.

Martinich, L. (2016). Excellent execution: Balancing top-down and bottom-up management. IEEE Engineering Management Review, 44(2), 20-22. doi:10.1109/EMR.2016.2568720

McCarthy, N. (2020, March 26). COVID-19's Staggering impact on global education. World Economic Forum. World Economic Forum [Blog post]. Retrieved from https://www.weforum.org/agenda/2020/03/infographic-covid19-coronavirus-impactglobal-education-health-schools/

Shaw, A. (2019). Scaffolding Learning in the Online Classroom. Center for Teaching and Learning. Retrieved from https://ctl.wiley.com/scaffolding-learning-in-the-onlineclassroom/

Shea, P., Sau Li, C., \& Pickett, A. (2006). A study of teaching presence and student sense of learning community in fully online and web-enhanced college courses. The Internet and Higher Education, 9, 175-190. doi:10.1016/j.iheduc.2006.06.005

Slagter van Tryon, P. J., \& Bishop, M. J. (2009). Theoretical foundations for enhancing social connectedness in online learning environments. Distance Education, 30(3), 291-315. doi:10.1080/01587910903236312

Thompson, T. L., \& MacDonald, C. J. (2005). Community building, emergent design and expecting the unexpected: Creating a quality eLearning experience. The Internet and Higher Education, 8(3), 233-249.

\section{Acknowledgements}

The authors gratefully acknowledge the support and contribution of Ms Giuliana Longworth, Professor Godfrey Baldacchino and Professor Fiona Smart. 